\title{
AVALIAÇÃO MICROBIOLÓGICA, FÍSICO-QUÍMICA E ACEITAÇÃO SENSORIAL DO KEFIR COM POLPA DE GRAVIOLA
}

\author{
Microbiological, physicochemical evaluation \\ and sensory acceptance of kefir with graviola pulp
}

\begin{abstract}
Luciana Silva Rocha Contim ${ }^{1 *}$, Ila Maria Aguiar Oliveira ${ }^{2}$, José Cardoso Neto
\end{abstract}
\section{RESUMO}

Kefir é um produto obtido através da fermentação do leite com os grãos de kefir e de culturas preparadas a partir dos grãos. Tendo em vista suas propriedades funcionais e buscando o aproveitamento de frutos da região amazônica, foi produzida uma bebida de kefir com graviola. Foram avaliadas as características microbiológicas, físico-químicas da bebida durante a estocagem refrigerada, bem como sua aceitabilidade. Os principais grupos de microrganismos presentes no kefir são bactérias lácticas como Lactobacillus, Lactococcus, leveduras, bactérias acéticas, que foram quantificadas através de contagem seletiva em meios de cultura específicos. Verificaram-se contagens similares para todos os grupos de bactérias, em torno de $10^{9} \mathrm{UFC} / \mathrm{mL}$ com redução de dois ciclos logaritmos ao final de 28 dias de estocagem. A adição da polpa de fruta e açúcar ao kefir não influenciou o comportamento da microbiota analisada. Bactérias láticas foram isoladas dos grãos de kefir. Os nove isolados foram caracterizados como Lactococcus lactis subp. lactis. Os valores de $\mathrm{pH}$ não variaram significativamente durante 21 dias, somente no $28^{\circ}$ dia de estocagem refrigerada, mas a acidez aumentou progressivamente durante todo período. A análise sensorial do kefir com polpa de graviola apresentou uma elevada aceitabilidade.

Palavras-chave: alimentos funcionais; leite fermentado; bactérias láticas.

1 Universidade Federal de Jataí, Unidade Acadêmica Especial de Ciências Bológicas, Cidade Universitária José Cruciano de Araújo, Rod BR 364 km 192, Setor Parque Industrial nº 3800, 75801-615, Jataí, GO, Brasil. E-mail: lucianacontim@ufg.br

2 Universidade Federal do Amazonas, Faculdade de Ciências Farmacêuticas, Manaus, AM, Brasil.

3 Universidade Federal do Amazonas, Instituto de Ciências Exatas, Departamento de Estatística, Manaus, AM, Brasil

* Autor para correspondência. 


\begin{abstract}
Kefir is a product obtained by fermentation of milk with kefir grains and cultures prepared from the grains. Considering the functional qualities of kefir and seeking the use of fruits from the Amazon region, a kefir beverage was produced with graviola pulp and its microbiological and physicochemical characteristics were evaluated during the storage period under refrigeration, as well as its acceptability. The main groups of microorganisms presented in kefir were Lactobacillus, Lactococcus, yeast and acetic bacteria quantified in specific broths. The total number of microorganisms was similar for all groups, around $10^{9} \mathrm{cfu} / \mathrm{g}$. At the end of 28 days of storage it was reduced to $10^{7} \mathrm{cfu} / \mathrm{g}$. It was verified that the addition of graviola pulp and sugar to the natural kefir did not influence the behavior of its microbiota. Nine lactic acid bacteria were isolated from the kefir grains and were characterized as Lactococcus lactis subps. lactis. The $\mathrm{pH}$ value did not change significantly during 21 days of storage. The $\mathrm{pH}$ statistically increased - only on the $28^{\text {th }}$ day of storage under refrigeration. The acidity ( $\%$ of lactic acid) increased gradually during the storage period. The sensory analysis of kefir with graviola pulp showed an excellent acceptability.
\end{abstract}

Keywords: functional foods; fermented milk; lactic acid bacteria.

\section{INTRODUÇÃO}

A fermentação é um dos métodos mais antigos para a preservação do leite. Em muitos países, uma grande variedade de leites fermentados é produzida e consumida devido às características sensoriais, ação terapêutica e importância econômica industrial.

O kefir é uma bebida láctea fermentada, obtida através de dupla fermentação: láctica e alcoólica. É originário das montanhas dos Caucasos na Rússia, onde é consumido há milhares de anos, sendo produzido pela fermentação dos grãos de kefir no leite ou pelo uso de cultura preparada a partir dos grãos (OTLES; CADING, 2003; IRIGOYEN et al., 2005; CHEN et al., 2009).

Os grãos do kefir são uma matriz constituída de proteína e polissacarídeo em forma de couve-flor, com 3 a 20 mm de diâmetro, onde bactérias ácido láticas (Lactobacillus, Lactococcus, Leuconostoc), bactérias acéticas e leveduras vivem em perfeita simbiose (PINTADO et al., 1996; ZANIRATI et al., 2015).
O resultado desta dupla fermentação é a produção de numerosos compostos incluindo ácido lático, ácido acético, $\mathrm{CO}_{2}$ e álcool etílico que dão sabor e aroma característicos ao produto.

As características microbiológicas do kefir variam de acordo com a origem dos grãos (GUZEL-SEYDIM et al., 2005; ZHOU et al., 2009; LUANG-IN; DEESEENTHUM, 2016) e porcentagem dos grãos inoculados (GARROTE et al., 1998). Outros fatores afetam significativamente a microbiota dos grãos de kefir, entre eles: tempo e temperatura de incubação, condições higiênico sanitárias usadas durante a separação dos grãos, lavagem dos grãos e estocagem refrigerada (GUZELSEYDIM et al., 2005; POWELL et al., 2007; LONDERO et al., 2012). Já a qualidade físico-química do kefir pode variar dependendo se o kefir é produzido com os grãos ou com uma cultura preparada a partir dos grãos. A porcentagem de grãos inoculados também influencia efetivamente nas características do kefir, (SIMOVA et al., 2002; IRIGOYEN et al., 2005). 
O kefir é considerado um alimento funcional, ou seja, além das funções nutricionais básicas, produz efeitos benéficos a saúde. Por longo tempo, a Rússia tem usado o kefir para o tratamento de uma extensa gama de doenças. Possui atividade antimicrobiana (GAMBA et al., 2016; MIAO et al., 2016), ação anti-inflamatória (CHEN et al., 2012, PRADO et al., 2016) e antioxidante (FAHMY; ISMAIL, 2015; SATIR; GUZELSEYDIM, 2015). No Brasil, o kefir ainda não é produzido em escala industrial, mas alguns trabalhos já têm sido desenvolvidos servindo de suporte para uma possível comercialização deste produto no mercado de produtos lácteos (WESCHENFELDER et al., 2011; LEITE et al., 2013).

Considerando as propriedades funcionais do kefir na alimentação humana e associando a isso, as características sensoriais da polpa da graviola, propôs-se um estudo visando à produção de kefir com essa fruta da Amazônia, avaliando a sua qualidade microbiológica, físico-química e a aceitabilidade do produto obtido.

\section{MATERIAL E MÉTODOS}

As amostras de grãos de kefir foram cedidas pelo Laboratório de Culturas Lácticas da Universidade Federal de Viçosa, Viçosa, MG. Para a manutenção dos grãos durante a realização do experimento, esses grãos foram repicados $\left(25^{\circ} \mathrm{C} / 24\right.$ horas $)$ em leite integral UHT (Ultra High Temperature) comercial, duas vezes por semana. Foram produzidas duas bebidas, um kefir natural (controle) e kefir com polpa de graviola, segundo metodologia descrita por Ferreira (2008).

Realizou-se o monitoramento dos principais grupos de microrganismos presentes no kefir durante o período de estocagem de 28 dias a $4{ }^{\circ} \mathrm{C}$. Foram feitas análises nos tempos $0,7,14,21$ e 28 dias de armazenagem refrigerada. A contagem de Lactobacillus foi realizada em ágar MRS (Man Rogosa Sharpe), pelo método de plaqueamento em profundidade, incubando-se a $30^{\circ} \mathrm{C}$, em anaerobiose, por 48 horas. Para contagem de Lactococcus pelo método de plaqueamento em profundidade, o meio de cultura utilizado foi o M17 ágar, sendo realizada a incubação em anaerobiose a $30^{\circ} \mathrm{C}$, por 48 horas (IRIGOYEN et al., 2005)

Para a determinação do número de leveduras, o meio utilizado foi MEA (Malt Extract Agar), incubando-se as placas em aerobiose por 5 dias a $25^{\circ} \mathrm{C}$ (PINTADO et al., 1996). As bactérias acéticas foram cultivadas em meio APM (Acetobacter Peroxim Médium) ágar e realizou-se a incubação 25 ${ }^{\circ} \mathrm{C}$ por 48 horas. A contagem dos microrganismos foi expressa em log de UFC/mL de kefir.

A determinação do teor alcoólico foi realizada através de destilação simples do kefir em destilador Tecnal TE-036/1 e medição do teor alcoólico em densímetro portátil para laboratório, modelo DM-340.2, versão V11 da LemisBaltic. As análises do $\mathrm{pH}$, acidez titulável, extrato seco total, lipídeos totais e resíduo mineral fixo foram feitas segundo a metodologia do Instituto Adolfo Lutz, (2008). O teor de proteína foi determinado pelo método de Silva et al. (1997) e o teor de carboidratos foi determinado pela diferença da soma dos demais componentes.

O valor calórico foi calculado pela soma das porcentagens de proteína bruta e carboidratos, multiplicados pelo fator 4 ( $\left.\mathrm{Kcal} \mathrm{g}^{-1}\right)$, somado ao teor de lipídios totais, multiplicado pelo fator $9\left(\mathrm{Kcal} \mathrm{g}^{-1}\right)$.

Para o isolamento das bactérias láticas, os grãos de kefir foram plaqueados em ágar MRS. Colônias características foram selecionadas e ativadas em caldo MRS. A identificação das bactérias lácticas foi realizada com base em testes bioquímicos do API ${ }^{\circledR}$ CHL50, (API ${ }^{\circledR}$ systems, bioMérieux).

O teste de aceitação do kefir com polpa de graviola foi realizado com cem 
provadores não treinados, utilizando-se uma escala hedônica de nove pontos $(9=$ excelente, $8=$ ótimo, $7=$ muito bom, $6=$ bom, $5=$ indiferente, $4=$ razoável, $3=$ ruim, 2 = muito ruim, $1=$ péssimo), adaptado por STONE; SIDEL (1985).

Os resultados de $\mathrm{pH}$, acidez e contagem de microrganismos foram avaliados utilizando-se análise de variância (ANOVA), com duas variáveis: tempo $(0,7,14,21$ e 28 dias) e produto (controle e bebida). As análises foram realizadas em triplicata e o teste de Tukey $(\mathrm{p}<0,05)$ foi aplicado para as comparações das médias.

\section{RESULTADOS E DISCUSSÃO}

A partir do isolamento realizado no kefir com polpa de graviola e/ou no kefir controle, constatou-se que todos os isolados eram Gram

(a)

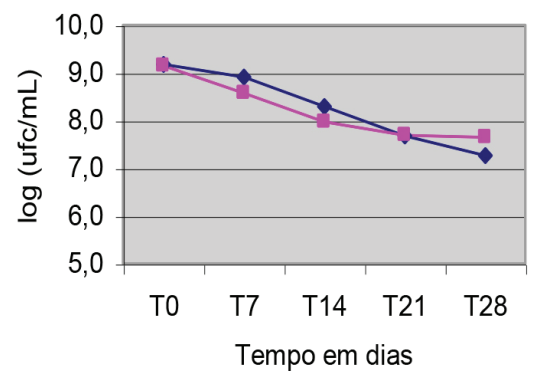

(c)

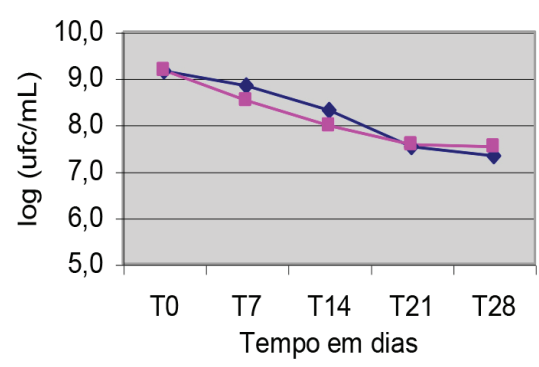

positivos e catalase negativos e apresentavamse na forma de cocos. Dentre os isolados foram observados os seguintes arranjos: $33,3 \%$ de estafilococos, $36,6 \%$ de estreptococos e $30 \%$ de cocos; não tendo sido detectados bacilos. Em contraste, grãos de kefir da Argentina possuíam número de bacilos duas vezes maior em relação ao de cocos (GARROTE et al., 2001). A diferença encontrada entre os grupos de microrganismos dos grãos de kefir pode ser explicada pela variação na origem dos grãos. Alguns isolados em forma de cocos foram selecionados para o teste de assimilação de carboidratos para bactérias lácticas. Todos os isolados submetidos ao teste API ${ }^{\circledR}$ CHL50 foram classificados como Lactococcus lactis subsp. lactis. Este microrganismo também foi identificado em grãos de kefir brasileiros, que além desta espécie apresentou: Leuconostoc mesenteroides, Lactococcus lactis subsp. (b)

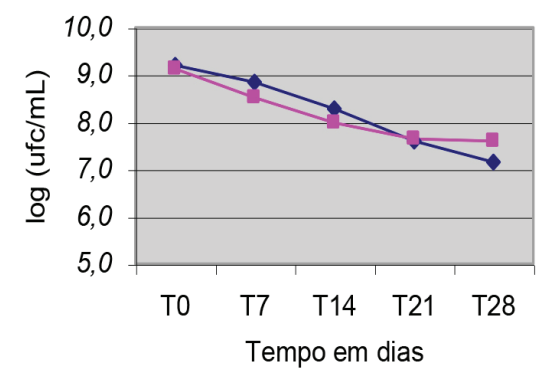

(d)

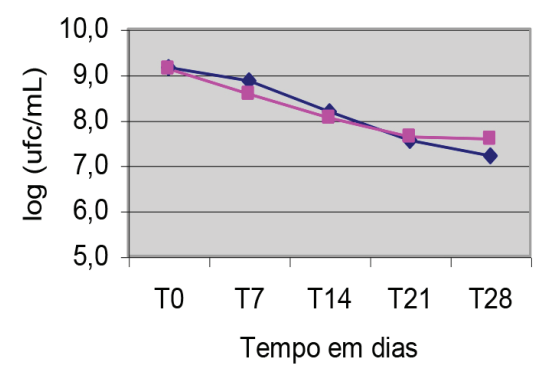

Figura 1 - Contagem de (a) Lactobacillus, (b) Lactococcus, (c) leveduras e (d) bactérias acéticas, durante o período de estocagem 
cremoris e Lactobacillus paracasei (LEITE et al., 2015).

Durante o período de estocagem refrigerada do kefir natural (controle) e do kefir com polpa de graviola (bebida) foram quantificados os microrganismos: Lactobacillus, Lactococcus, bactérias acéticas e leveduras, nos tempos $0,7,14,21$ e 28 dias e os resultados expressos em log UFC/mL (Figura 1).

Pela análise de variância (ANOVA) observou-se que não houve influência do tipo de produto (controle e bebida) no crescimento de nenhum dos grupos de microrganismos analisados $(p<0,05)$. A contagem inicial (tempo 0) dos grupos de microrganismos: Lactobacillus, Lactococcus, bactérias acéticas e leveduras foi em torno de $10^{9} \mathrm{UFC} / \mathrm{mL}$ (Figura 1). Este valor está próximo ao observado por Garrote et al. (1998), Fontán et al. (2006); Irigoyen et al. (2005) em relação ao número de Lactobacillus e Lactococcus, que foi em torno de $10^{8} \mathrm{UFC} / \mathrm{mL}$. No entanto, as contagens de leveduras e bactérias acéticas foram superiores aos valores observados por Garrote et al. (1998); Irigoyen et al. (2005). Estes autores constataram contagem de leveduras e bactérias acéticas de $10^{5}$ e $10^{6} \mathrm{UFC} /$ $\mathrm{mL}$, respectivamente. Beshkova et al. (2002), também relataram contagem de $10^{8} \mathrm{UFC} /$ $\mathrm{mL}$ para Lactobacillus e $10^{5} \mathrm{UFC} / \mathrm{mL}$ para leveduras, contudo um número maior para os Lactococcus $10^{11} \mathrm{UFC} / \mathrm{mL}$. O número de microrganismos diminuiu significativamente, $(\mathrm{p}<0,05)$ ao longo do tempo, até 21 dias de estocagem, sendo que nos tempos 21 e 28 dias não houve diferença significativa $(\mathrm{p}>0,05)$ no número de microrganismos encontrados. Irigoyen et al. (2005), observaram um declínio significativo no número de Lactobacillus e Lactococcus até 14 dias de estocagem refrigerada, enquanto que a população de leveduras e bactérias acéticas permaneceu constante durante todo o período de estocagem.

No final do período de armazenagem (28 dias) todos os grupos de microrganismos tiveram contagem em torno de $10^{7} \mathrm{UFC} / \mathrm{mL}$ para todas as populações microbianas avaliadas. Portanto, o kefir de graviola está de acordo com legislação vigente (BRASIL, 2007) que estabelece que as contagens de bactérias láticas totais e de leveduras durante o seu período de validade deverão ser, de no mínimo $10^{7}$ e $10^{4} \mathrm{UFC} / \mathrm{g}$ de kefir, respectivamente.

As contagens finais obtidas no kefir controle e bebida foram superiores aos valores encontrados por Irigoyen et al. (2005), que ao final de 28 dias de estocagem sob refrigeração observaram contagem entre $10^{4}$ a $10^{6} \mathrm{UFC} / \mathrm{mL}$. Este decréscimo observado neste trabalho, no número de microrganismos, pode ser atribuído ao aumento da acidez e a diminuição de substrato no meio o que também foi observado por Kok-Tasetal (2013).

A composição centesimal do kefir natural e do kefir com polpa de graviola está apresentada na Tabela 1.

O kefir natural diferiu do kefir com polpa de graviola pela adição de dois ingredientes,

Tabela 1 - Composição química e energética do kefir natural (controle) e do kefir com polpa de graviola $^{a}$ (bebida)

\begin{tabular}{lcccccc}
\hline & Água & Gordura & Cinzas & Proteína & Carboidratos & Valor Calórico $^{\mathrm{b}}$ \\
\hline Controle & 86,50 & 3,50 & 0,63 & 3,04 & 6,33 & 69,00 \\
\hline Bebida & 88,30 & 3,00 & 0,42 & 2,32 & 5,96 & 60,00 \\
\hline
\end{tabular}

a: os valores foram expressos em $\mathrm{g} / 100 \mathrm{~g}$

b: O valor calórico foi expresso em $\mathrm{kcal} / 100 \mathrm{~g}$ 
o açúcar e a polpa de graviola. A polpa de graviola contendo alto teor de umidade, adicionado ao kefir natural, aumentou seu conteúdo de água e, consequentemente, diluiu a concentração de todos os macronutrientes, como pode ser observado na Tabela 1.

Os resultados da análise centesimal do kefir natural estão de acordo com os dados apresentados por Satir; Guzel-Seydim (2016), com exceção do teor de lipídeos, que foi ligeiramente superior ao observado pelos autores, entre 2,8-3,3\%. Esta pequena variação é normal e pode ser atribuída ao teor de gordura do leite utilizado na preparação do kefir.

Também se constatou que o kefir de graviola atendeu aos padrões estabelecidos no Regulamento Técnico de Identidade e Qualidade de Leites Fermentados. (BRASIL, 2007), no que se refere ao teor de proteínas (mínimo de 2,9\%) e matéria gorda (3,0 a $5,9 \%)$. Os demais parâmetros analisados e apresentados na Tabela 1 não estão contemplados na referida legislação.

A porcentagem de álcool no controle e na bebida foi de 0,10 e $0,20 \%$, respectivamente. A concentração de álcool na bebida foi maior em relação ao controle, possivelmente pela adição de açúcar na bebida, o que favoreceu a fermentação e produção de álcool. Simova et al. (2002) observaram diferença significativa no teor alcoólico do kefir produzido utilizando-se, separadamente, os grãos e outro kefir como inóculo, sendo que os valores variaram entre $0,25 \%$ a $0,09 \%$, respectivamente. Esta diminuição no teor alcoólico, quando foi empregado outro kefir como inóculo, foi atribuída à diminuição no número de leveduras presentes no processo fermentativo.

Os valores de $\mathrm{pH}$ do controle e da bebida foram submetidos à análise de variância utilizando-se $5 \%$ de probabilidade. Não houve diferença significativa $(\mathrm{p}>0,05)$ no $\mathrm{pH}$ das bebidas ao longo da estocagem refrigerada, havendo diferença significativa somente no tempo de 28 dias. O tipo de produto (controle e bebida) influenciou significativamente $(\mathrm{p}<0,05)$ na variação do $\mathrm{pH}$ durante o período de estocagem.

$\mathrm{O} \mathrm{pH}$ de alguns leites fermentados tais como o iogurte e o labneh tende a diminuir significativamente durante o período de estocagem refrigerada (KATISIARI et al., 2002; AL-KANAMANY et al., 2003). No entanto, neste trabalho, o $\mathrm{pH}$ no $28^{\circ}$ dia de estocagem refrigerada apresentou um discreto aumento, conforme indica a Tabela 2. Irigoyen et al. (2005), sugerem que esta diferença de variação do $\mathrm{pH}$ de outros leites fermentados quando comparado ao kefir, durante o período de estocagem refrigerada, deve-se a presença de leveduras, que produzem substância com capacidade tamponante.

A acidez titulável das amostras avaliadas aumentou progressivamente durante os 28 dias de estocagem com valores que variaram de 1,27 a $1,48 \%$ de ácido láctico no controle e de 1,25 a $1,41 \%$ de ácido láctico, na bebida, conforme mostra a Tabela 3 .

Tabela 2 - Valores de pH durante o tempo (dias) de estocagem refrigerada do kefir natural (controle) e do kefir com polpa de graviola (bebida)

\begin{tabular}{lccccc}
\hline & T0 & T7 & T14 & T21 & T28 \\
\hline Controle & $4,25^{\mathrm{a}}$ & $4,29^{\mathrm{a}}$ & $4,28^{\mathrm{a}}$ & $4,24^{\mathrm{a}}$ & $4,31^{\mathrm{b}}$ \\
\hline Bebida & $4,19^{\mathrm{a}}$ & $4,19^{\mathrm{a}}$ & $4,24^{\mathrm{a}}$ & $4,24^{\mathrm{a}}$ & $4,30^{\mathrm{b}}$ \\
\hline
\end{tabular}

a Valores com sobrescritos diferentes em uma mesma linha são estatisticamente diferentes, em relação ao tempo de estocagem, de acordo com o teste de Tukey $(\mathrm{p}<0,05)$. 
Tabela 3 - Valores da acidez titulável, expresso em \% de ácido lático, durante o tempo (dias) de estocagem refrigerada do controle e da bebida

\begin{tabular}{lccccc}
\hline & T0 & T7 & T14 & T21 & T28 \\
\hline Controle & $1,27^{\mathrm{a}}$ & $1,42^{\mathrm{b}}$ & $1,42^{\mathrm{b}}$ & $1,48^{\mathrm{b}}$ & $1,48^{\mathrm{b}}$ \\
\hline Bebida & $1,25^{\mathrm{a}}$ & $1,32^{\mathrm{b}}$ & $1,35^{\mathrm{b}}$ & $1,40^{\mathrm{b}}$ & $1,41^{\mathrm{b}}$ \\
\hline
\end{tabular}

${ }^{a}$ Valores com sobrescritos diferentes em uma mesma linha diferem estatisticamente, em relação ao tempo de estocagem de acordo com o teste de Tukey $(\mathrm{p}<0,05)$.

Estes valores estão acima do determinado pela legislação brasileira, que é de $1 \mathrm{~g}$ de ácido láctico por 100 gramas do produto (Brasil, 2007). Outros trabalhos realizados na produção de kefir com grãos de kefir brasileiros, também obtiveram produtos com acidez acima da preconizada pela legislação vigente, entre eles, Martins et al. (2012) e Weschenfelder et al. (2011). Entretanto Rocha et al. (2014) observaram valores de acidez para kefir integral e desnatado entre 0,75 e $0,91 \%$ de ácido láctico, respectivamente, após 24 horas se fermentação.

O kefir elaborado com polpa de graviola de acordo com a escala empregada foi classificado como ótimo, com valor médio de 8,3. Os atributos sensoriais de leites fermentados, em geral, são influenciados, significativamente, pelo tipo de cultura lática utilizada no processo fermentativo. A fermentação láctica produz diversos ácidos orgânicos, tais como: ácido cítrico, ácido pirúvico, ácido lático, ácido acético dentre outros, que vão influenciar diretamente no sabor e odor dos leites fermentados (TORRES, 2003). Os microrganismos envolvidos nos processos de fermentação, bem como os seus metabólitos gerados, principalmente ácidos acético e láctico exercem uma forte influência nas características sensoriais únicas do produto final. Estes podem servir como base para o futuro da produção industrial desta bebida no Brasil (LEITE et al., 2013).

\section{CONCLUSÕES}

Todos os isolados submetidos ao teste de assimilação de carboidratos, dos grãos de kefir, foram identificados como Lactococcus lactis subsp. lactis sendo, possivelmente, o microrganismo predominante na microbiota dos grãos de kefir em estudo.

A adição de polpa de fruta e açúcar ao kefir não influenciou no crescimento dos grupos de microrganismos analisados: Lactobacillus, Lactococcus, leveduras e bactérias acéticas. Todos os grupos de microrganismos avaliados obtiveram contagem aproximada de $10^{9} \mathrm{UFC} / \mathrm{mL}$ no início do período de estocagem (tempo 0) decrescendo para aproximadamente $10^{7} \mathrm{UFC} / \mathrm{mL}$ após 28 dias de armazenagem sob refrigeração.

A análise sensorial do kefir de graviola constatou que esta bebida apresentou elevada aceitação, indicando potencial para comercialização.

\section{REFERÊNCIAS}

AL-KANAMANY, E. et al. Estimation of shelf-life of concentrated yogurt by monitoring selected microbiological and physicochemical changes during storage. LWT - Food Science and Technology, v. 36, p. 407-414, 2003.

BESHKOVA, D. M. et al. Pure cultures for making kefir. Food Microbiology, v. 19, p. 537-544, 2002. 
BRASIL. Ministério da Agricultura, Pecuária e Abastecimento. Instrução Normativa $\mathrm{n}^{\mathrm{o}} 46$, de 23 de outubro de 2007. Aprova o Regulamento Técnico de Identidade e Qualidade de Leites Fermentados. Diário Oficial da República Federativa do Brasil, Brasília, 24 out. 2007 . Seção 1, p. 5.

CHEN, T. H. et al. Microbiological and chemical properties of kefir manufactured by entrapped microorganisms isolated from kefir grains, Journal of Dairy Science, v. 92, p. 3002-3013, 2009.

CHEN, Y. P. et al. Lactobacillus kefiranofaciens M1 isolated from milk kefir grains ameliorates experimental colitis in vitro and in vivo. Journal of Dairy Science, v. 95, p. 63-74, 2012.

FAHMY, H. A.; ISMAIL, A. F. M. Gastroprotective effect of kefir on ulcer induced in irradiated rats. Journal of Photochemistry and Photobiology B: Biology, v. 144, p. 8593, 2015.

FERREIRA, C. L. L. F. Produtos lácteos fermentados: aspectos bioquímicos e tecnológicos. $3^{\mathrm{a}}$ ed. Viçosa: Editora Universitária, 2008 .

FONTÁN, M. C. G et al. Microbiological and chemical changes during the manufacture of kefir made from cows, milk, using a commercial starter culture. International Dairy Journal, v. 16, p. 762-767, 2006.

GAMBA, R. R. et al. Antifungal effect of kefir fermented milk and shelf life improvement of corn arepas. International Journal of Food Microbiology, v. 235, p. 85-92, 2016.

GARRote, G.; ABRAHAM, A.; DE ANTONI, G. L. Characteristics of kefir prepared with different grain: milk ratios. Journal of Dairy Research, v. 65, p. 149-154, 1998.

GARROTE, G.; ABRAHAM, A.; DE ANTONI, G. L. Chemical and microbiological characterization of grains.Journal of Dairy Research, v. 68, p. 639-652, 2001.

GUZEL-SEYDIM, Z. et al. Kefir and kefir grains: microbial enumeration and electron microscopic observation. International Journal of DairyTechnology, v. 58, p. 275-277, 2005.

INStituto ADOLFO LUTZ. Métodos físico-químicos para análise de alimentos, $4^{\mathrm{a}}$ ed. $1^{\mathrm{a}}$ Edição eletrônica, São Paulo: IAL, 2008. 1020 p.

IRIGOYEN, A. et al. Microbiological, physicochemical, and sensory characteristics of kefir during storage. Food Chemistry, v. 90, p. 613-620, 2005.

KATSIARI, M. C.; VOUTSINAS, L. P.; KONDYLI, E. Manufacture of yoghurt from stored frozen sheep's milk. Food Chemistry, v. 77, p. 413-420, 2002.

KOK-TAS, T. et al. Effects of different fermentation parameters on quality characteristics of kefir. Journal Dairy Science, v. 96, p. 780-789, 2013.

LEITE, A. M. O. et al. Microbiological and chemical characteristics of Brazilian kefir during fermentation and storage processes. Journal Dairy Science, v. 96, p. 4149-4159, 2013.

LEITE, A. M. O. et al. Probiotic potential of selected lactic acid bacteria strains isolated from Brazilian kefir grains. Journal Dairy Science, v. 98, p. 3622-3632, 2015.

LONDERO, A. et al. Kefir grains as a starter for whey fermentation at different 
temperatures: chemical and microbiological characterisation. Journal of Dairy Research, v. 79, p. 262-271, 2012.

LUANG-IN, V.; DEESEENTHUM, S. Exopolysaccharide-producing isolates from Thai milk kefir and their antioxidant activities. LWT - Food Science and Technology, v. 73, p. 592-601, 2016.

MARTINS, J. F. L. et al. Avaliação da adição de kefir em dieta hospitalar. Revista do Instituto de Laticínios Cândico Tostes, v. 67, p. 13-19, 2012.

MIAO, J. et al. Inhibitory effects of a novel antimicrobial peptide from kefir against Escherichia coli. Food Control, v. 65, p. 6372, 2016.

OTLES, S.; CADINGI, O. kefir: A probiotic dairy-composition nutritional and therapeutic aspects. Pakistan Journal of Nutrition, v. 2, p. 54-59, 2003.

PINTADO, M. E. et al. Microbiological and rheological studies on Portuguese kefir grains. International Journal of Food Science and Technology, v. 31, p. 15-26, 1996.

POWELL, J. E. et al. Characterization of bacteriocin ST8KF produced by a kefir isolate Lactobacillus plantarum ST8KF. International Dairy Journal, v. 17, p. 190-198, 2007.

PRADO, M. R. M. et al. Anti-inflammatory and angiogenic activity of polysaccharide extract obtained from Tibetan kefir. Microvascular Research, v. 108, p. 29-33, 2016.

ROCHA, D. M. U. et al. Labneh with probiotic properties produced from kefir: development and sensory evaluation. Food Science and Technology, v. 34, p. 694-700, 2014.
SATIR, G.; GUZEL-SEYDIM, B. Z. Influence of kefir fermentation on the bioactive substances of different breed goat milks. LWT - Food Science and Technology, v. 63, p. 852-858, 2015.

SATIR, G.; GUZEL-SEYDIM, B. Z. How kefir fermentation can affect product composition? Small Ruminant Research, v. 134, p. 1-7, 2016.

SIMOVA, E. et al. Lacti acid bactéria and yeasts in kefir grains and kefir made from them. Journal of Industrial Microbiology \& Biotechnology, v. 28, p. 1-6, 2002.

SILVA, P. H. F. et al. Físico-química do leite e derivados - métodos analíticos. Juiz de Fora: Oficina de Impressão Gráfica, 1997.

STONE, H.; SIDEL, J. L. Sensory evaluation practices. Redwood: Academic Press, 1985, 408p.

TORRES, L. L.; TAMINE, Y. A.; MUIR, D. D. Rheology and sensory profiling of set-type fermented milks made with different commercial probiotic and yoghurt starter cultures. International Journal of DairyTechnology, v. 56, p. 163-170, 2003.

WESCHENFELDER, S. et al. Caracterização físico-química e sensorial de kefir tradicional e derivados. Arquivo Brasileiro de Medicina Veterinária e Zootecnia, v. 63, p. 473-480, 2011.

ZANIRATI, D. F. et al. Selection of lactic acid bacteria from Brazilian kefir grains for potential use as starter or probiotic cultures. Anaerobe, v. 32, p. 70-76, 2015.

ZHOU, J. et al. Analysis of the microflora in Tibetan kefir grains using denaturing gradient gel electrophoresis. Food Microbiology, v. 26, p. 770-775, 2009. 